\title{
A Main Street framework leveraging data and technology for good
}

\author{
Fadi G. Haddad ${ }^{1, *}$, Zara Raheem ${ }^{2}$, Peter J. Mattingly ${ }^{3}$, Saswati Mishra ${ }^{4}$, and Medha Patki ${ }^{5}$ \\ Edited by Juste Rajaonson and Yana Petri
}

\section{HIGHLIGHTS}

- As major US firms embraced a remote work culture in the wake of COVID-19, many dependent small and local businesses-known as Main Street businesses-were negatively affected.

- In urban centers like Seattle, the spillover effects revealed systemic challenges and inequities affecting places, profits, and diverse people, which require tailored policy responses.

- A data-driven Main Street framework can support policymakers in better assessing and supporting both urban vitality and equity objectives, including through targeted technology policy initiatives.

- Equity analysis strategies can complement such efforts by ensuring equity aspirations translate into more inclusive recovery strategies in the future of work.

The COVID-19 pandemic has hollowed out corporate office spaces in large US metropolitan centers, resulting in three potential downstream differential impacts: (1) on places, as demand for urban office spaces, commercial real estate, and housing have changed; (2) on profits, as small and local businesses in proximity to these office spaces depend on office workers and other foot traffic; and, (3) on people, as the livelihoods of many diverse but historically marginalized communities have been disproportionately affected. In this article, we examine these impacts, with downtown Seattle used as a case study to validate some urban trends. In leveraging data and technology-based approaches to assess and support urban vitality and equity goals, policymakers can explore the value of a Main Street data-driven analytical framework. Here, we explore how such a framework can support more targeted responses, including

\footnotetext{
${ }^{1}$ Policy, Economic Intelligence and Results, Canada Economic Development for Quebec Regions, Montreal, QC

${ }^{2}$ Lahore School of Economics, Lahore, PK

${ }^{3}$ Schack Institute of Real Estate, New York University, New York City, NY

${ }^{4}$ Good Business Lab, Bangalore, IN

${ }^{5}$ Kennedy School of Government, Harvard University, Cambridge, MA

*Email: fady.ghaddad@gmail.com

The authors declare no conflict of interest. The views expressed herein are solely those of the authors and do not necessarily represent the views of any affiliated organizations.
}

(c) 2021 The Author(s) implementing technology policy initiatives that increase the digitalization of Main Street businesses and support their resilience. Complementing this data-driven framework, institutionalizing equity analysis in regional decision-making systems can better account for differential impacts on vulnerable communities to implement more inclusive future of work recovery strategies.

A $t$ the onset of the pandemic, major corporations in large US metropolitan areas promptly embraced a remote work culture to respect restrictive public health protocols. In a city like Seattle, which houses high-tech firms like Amazon and Microsoft, $90 \%$ of the 47 million square feet of leased office space was reportedly vacated, leaving nearby Main Street businesses struggling [1]. Looking at national trends and Seattle, we present COVID-19's compounding systemic challenges and spillover effects on places, people, and profits. We also explore how a Main Street data-driven framework can enhance policymakers' capacity in better assessing and responding to these differential impacts while supporting urban vitality and equity objectives.

Downstream impacts of changing urban workspaces on central places, small businesses profits, and historically marginalized people

COVID-19 transformed many urban workspaces: in May 2020 , 35\% of the US population worked from home compared to just $8 \%$ in February 2020 [2]. This sudden shift resulted in three differential downstream impacts, including the economic and social structures of urban places, the profitability of small and local businesses in urban centers, and the livelihoods of the people who inhabit these places.

\section{Impact on Places: the changing economic and social structures of urban areas}

As discussed below, the first downstream impact of the telework shift altered the demand for office spaces, commercial real estate, and housing, both nationally and in Seattle. Historically marginalized communities may be at increased displacement risk because they were most affected by such changes in the past.

Shifting demand for urban office spaces: When about 
half of the adult population in US major cities shifted to telework [3], the average demand for leased office spaces fell by $85 \%$ from its pre-pandemic levels [4]. In the case of Seattle, which hosts high-tech firms and where most workers quickly transitioned to telework, leased office space demand plummeted by $88 \%$ [4]. It is unclear to what extent these impacts are temporary, however, as corporations start seeing a possible return of their workers to office spaces in the short-term; leased US office space demand recovered to almost pre-pandemic levels in April 2021, with Seattle even exceeding these levels [4].

Devalued commercial real estate: With the decreased demand for office space with COVID-19 lockdowns, US commercial spaces in city centers saw an $83 \%$ increase in subleasing since 2020 [5]. In Seattle, for instance, office space available for sublease increased by a record $47 \%$ in October 2020 , the highest in the last 15 years [6]. Small, supportive businesses in US city centers were impacted in two ways. First, businesses relying on physical proximity, like retail and restaurants, could not adapt to social distancing norms and reported financial difficulties [7]. Second, as commercial property valuations in areas with higher COVID-19 incidence declined, supportive businesses exited the market rather than subleasing, even though they received lower valuations for their shops [8]. Nationally, this resulted in a systematic impact on minority business owners: $41 \%$ of Black-owned businesses and $32 \%$ of Latino-owned businesses shut down compared to only $17 \%$ of White-owned ones [9].

Housing market trends likely to change post-COVID-19: Compared to 2019, sales of houses in the US in 2020 fell by approximately $26 \%$ [10], and median rent prices declined by $4 \%$ in urban areas [11]. This was largely driven by a diminished need for living close to telework-compatible jobs and the declining value of access to consumption amenities [10,11]. Seattle was among the hardest-hit cities as rent prices fell by $19 \%$ since the pandemic began [12], suggesting a population exodus-at least temporarily-which can put additional pressures on Main Street businesses that who depend on nearby residential dwellers.

Displacement risk for marginalized communities: The cumulative impacts of the above changes may result in a high risk of displacement of marginalized communities. In the past decade, the Black and Latino population in the US was already vulnerable, constituting more than $80 \%$ of the population facing eviction [13]. In Seattle, communities of color and low-income residents have been the most displaced from past neighborhood changes such as population growth and increased employment, creating a job-housing imbalance in high density areas [14]. Because these communities in Seattle have had to bear the burden of long commutes and increased job insecurity [15], regional policies can better account for their specialized needs.

\section{Impact on Profits: varying profit-losses and inequitable access to relief for small businesses}

The pandemic crisis has also affected business profits unevenly, as many small and local businesses faced varying profit-losses and inequitable access to financial relief.

Liquidity challenges of small businesses: First, even before the pandemic, financially distressed US businesses feared relying on the owner's personal funds to continue operating [16]. Yet, $75 \%$ of business owners have used such funds since the COVID-19 lockdown, and almost half have had to scale back their operations [17]. This was damaging not only for the owners but also to the American economy, because these losses and expectations of future losses automatically instigated them to consume less [18]. Similarly, small businesses in Seattle were left vulnerable as soon as there was a dip in sales, simply because these businesses reportedly lack consistent revenue streams and rely on the owners' personal savings in the face of a disruption [16].

\section{Small businesses revenue and transit mobility:}

Second, small businesses that rely on foot traffic and lack an online presence, such as retail, accommodation, and food services, were hit the hardest following state shutdowns [17]. For these businesses, a reduced customer base will continue to increase revenue losses [18]. Looking at Apple Mobility data for Seattle, we observe a strong positive correlation between transit mobility and small businesses' revenue (Figure 1) [3], which we hypothesize as reflective of how these businesses are highly dependent on the mobility of their customers to generate revenue, which diminished following COVID-19 restrictions.

Relief to small businesses reveal inequities: Finally, because of the lack of clarity and awareness surrounding federal business relief and stimulus measures, US small businesses bore the brunt of profit losses and systemic failures [20]. Yet, for most minority-owned businesses, relief packages were meant to be a lifeline because they did not have the resources to stay afloat [17]. At the same time, the administration of the relief funds was left at the discretion of banks 


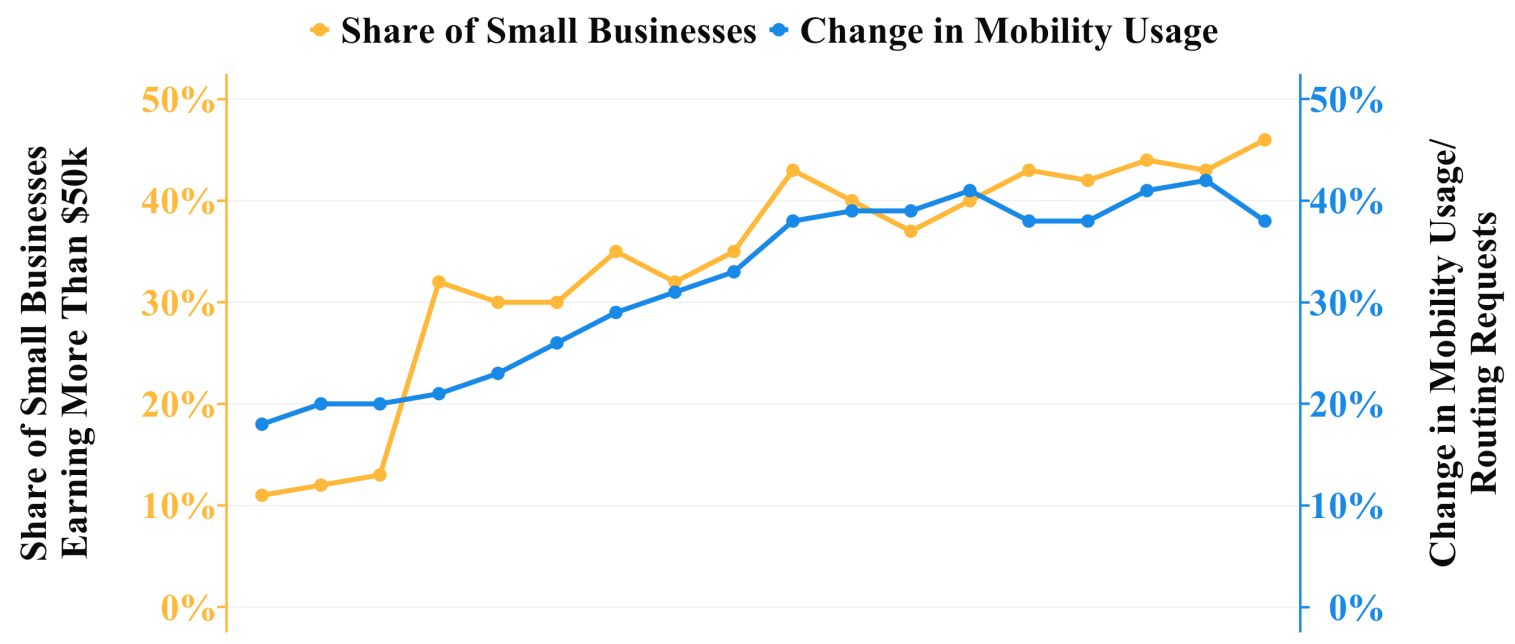

\section{$\begin{array}{llllllllllllllllll}1 & 2 & 3 & 4 & 5 & 6 & 7 & 8 & 9 & 10 & 11 & 12 & 13 & 14 & 15 & 16 & 17 & 18\end{array}$ \\ Week}

Figure 1 Share of small business revenue in Seattle by transit mobility usage $[3,19]$.

where minority communities have long faced systemic discrimination [21]. In Seattle, evidence of systemic barriers in relief faced by minority-owned businesses may have been observed as they received one-third of the total disbursed Paycheck Protection Program (PPP) loans (Figure 2).

\American Indian $\square$ Black $\square$ Latinx/Hispanic $\square$ Asian $\square$ White

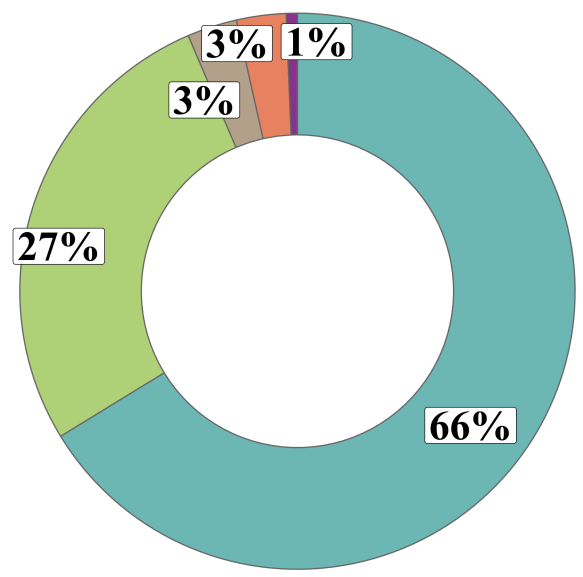

Figure 2: Share of small businesses receiving pandemic relief, by owner's race \& ethnicity: Paycheck Protection Program (PPP) loan distribution in Seattle, 2020 [22].

\section{Impact on People: historically marginalized communities disproportionately affected}

The third downstream impact is on people, and historically marginalized communities were significantly affected. As described below, COVID-19 highlighted long-standing systemic inequities that have been overlooked but are detrimental to businesses owned and jobs performed by them.

Systemic challenges for businesses: In major US urban centers, the impacts on businesses owned by minority communities have been amplified following COVID-19 lockdowns [23]. Given the differences in industry distribution and the scale of businesses, the highest impacts were felt by African-American and Latinx communities [24]. These minority-owned businesses are generally smaller and lack the resources to sustain themselves [23]. Even before the pandemic, 57\% Black-owned and 49\% Hispanic-owned US businesses were categorized as distressed or "at-risk" [25]. In Seattle, with the onset of the pandemic, pre-existing challenges were even more pronounced for communities of color that were more prone to incidences of COVID-19 [16]. Not only did employees in these businesses face job losses, but lower credit scores meant they were unable to secure loans that would allow them to adapt and weather any losses [16].

Systemic challenges for workers: As for workers from historically marginalized groups in the US, they are based in jobs that are less likely to accommodate remote work, indicating more profound social inequities exacerbated by the pandemic [26]. Even though a third of the US workforce worked entirely from home, White individuals were more successful in maintaining their jobs [27]: minorities accounted for $37 \%$ of the labor force in February 2020 yet represented 58\% of newly unemployed workers [28]. As firms made efforts to limit the shock felt by permanent workers, job losses were felt more by precarious workers, including those without a university degree, and women (i.e., $25 \%$ of women were either considering downshifting 


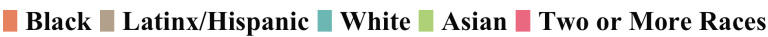

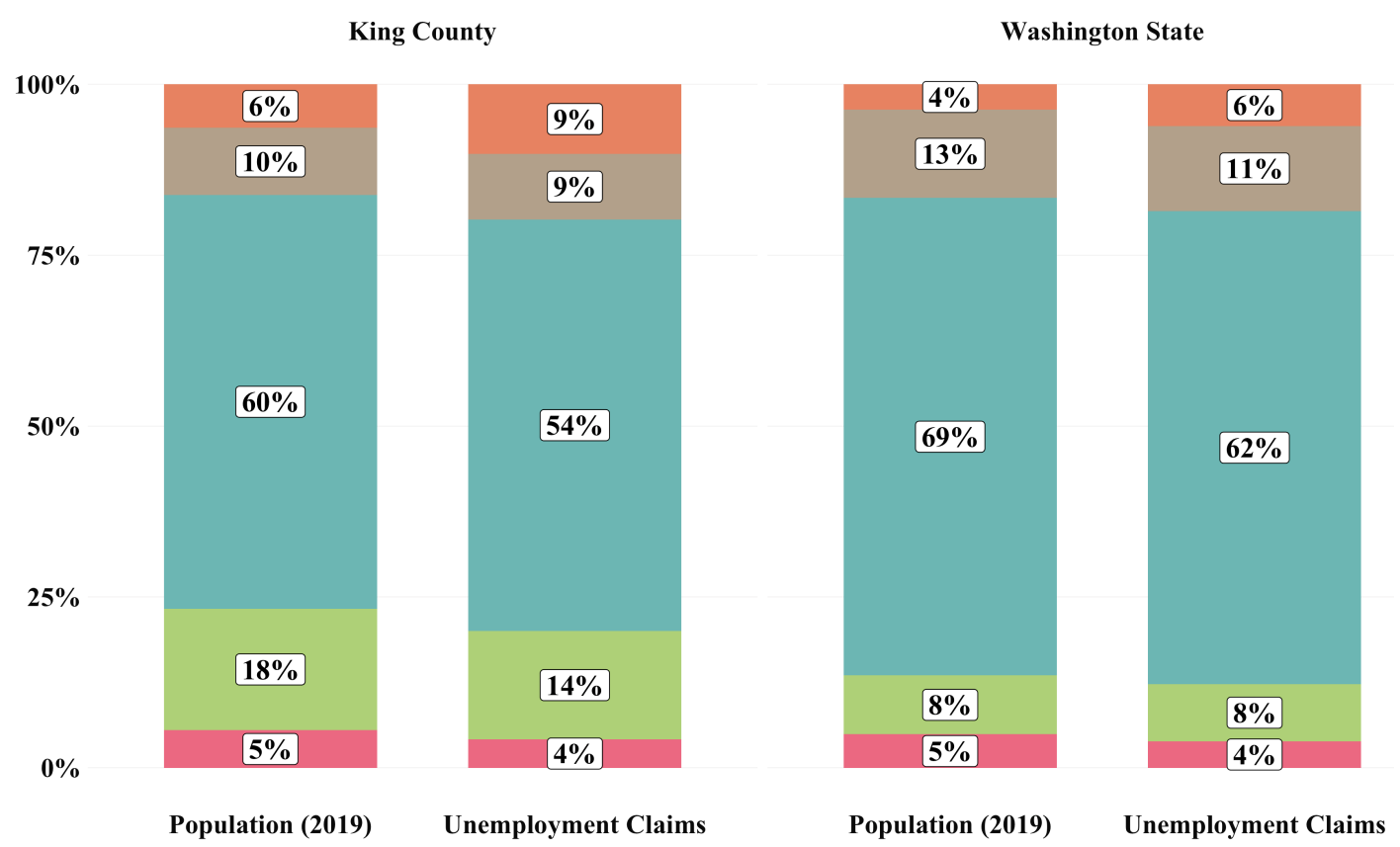

Figure 3: Share of Initial Weekly Unemployment Claims and Populations in King County and Washington State, by Race and Ethnicity [31]. The 2019 US population is: Black (13\%), Latinx/Hispanic (19\%), White (60\%), Asian (6\%), and Two or More Races (3\%) [32].

their careers or leaving the workforce [29]). Looking at both Washington State and King County (i.e., Seattle), communities of color were facing more job losses than their White counterparts (Figure 3). For Black or African American communities in Seattle, the share of Unemployment Insurance claims exceeded their overall representation, further underscoring how disproportionately the pandemic's impacts are spread based on individual characteristics [30].

\section{A Main Street analytical framework to support urban vitality and equity goals}

Small, local, independent businesses-known as Main Street businesses-are considered the central tenants of urban commercial districts that play a primordial role in these districts' lives, given their ability to attract residents and promote investments [33]. We observed earlier that these businesses were likely to be disproportionately impacted. Thus, regional policymakers concerned about assessing and addressing the downstream differential impacts of changing urban workspaces on places, profits, and people can be more sensitive to their needs with a Main Street analytical framework leveraging data and technology-oriented responses.

\section{Focusing on Main Street: a place, people, and profit-based revitalization response}

Main Street-focused policies are already recognized as both a place-based and people-based response to revitalization [33,34]. Because such policies have resulted in substantial investments as well as business and job creation in 1,600 US commercial districts facing decline [33], we argue they also support a profit-based response. Hence, focusing on assessing and monitoring the health of Main Streets can better support urban vitality and equity goals for two reasons.

First, supporting Main Street businesses can foster economic resilience [35], including in the COVID-19 era: their economic contributions are significant, making about $18 \%$ of all US business owners with earnings amounting to $12.5 \%$ of all business earnings [36]. They also have qualitative characteristics that contribute to urban vitality, including their: (1) uniqueness; (2) engaging street environments; (3) staff friendliness and familiarity; and, (4) sensitivity to community needs [36].

Second, because of the nature of their activities, a significant portion of Main Street businesses are owned by minority-owned groups or employ these groups, such as in Seattle, where nearly $48 \%$ of accommodation and food services firms are minority-owned [37]. Further, immigrants have supported Main Street businesses' growth in 31 of the 50 largest metropolitan areas [37]. In other words, support for Main Street can contribute to societal and economic objectives, as a community's openness, diversity, and inclusiveness can drive regional innovation and growth [38]. 
Main Street qualitative and quantitative characteristics

Business

size

Small and likely to be under 50 staff [37].

Main Street businesses and corridors typically have

Industry amenities that support daily life like restaurants, grocery stores, and community-oriented spaces [35].

Local sales Sales made within a localized area [40].

Main Street areas have an independent business share of at least $50 \%$ of total establishments, typically accounting for up to $80 \%$ or more of total establishments [35, 39].

Walkability

About $30 \%$ of Main Street customers live within 800 meters [39].

Tend to be residential and commercial in use, where shops are within buildings that house residential units, in contrast to other commercial corridors with chain stores and lack residential uses [35].

Business owners' and workers' disaggregated Equity demographic data can account for differential and other impacts. Other metrics include: the office vacancy factors rate, sales of these businesses, population density, business bankruptcies, and mobile movement data.

\section{Data availability considerations}

The US Small Business Administration and the US Census Bureau (e.g. Business Register, Statistics of US Businesses).

North American Industry Classification System (NAICS) to identify businesses in retail trade; accommodation and food services; arts, entertainment and recreation; and, other services [36].

Tracking local consumer sales data through third party payment processors, segmented by industry and geographical location.

Qualitative sources listing names of chains can segment chain stores from independent businesses [35].

Walkscore ${ }^{\mathrm{TM}}$ data can assess walkability measures that support the viability of Main Street businesses [35].

Municipal zoning maps and data sources, variable and dependent on local jurisdiction(s).

Can build on existing Main Street statistical and quantitative-based research [35], developed in consultation with local communities, stakeholders, and data experts.

TABLE I: Considerations for developing a Main Street data-driven dashboard to gain place, people, and profit-based insights in the context of COVID-19 and beyond.

\section{Data for good: devising a data-driven Main Street analytical framework}

Policymaking decisions relying on macroeconomic indicators like GDP and employment growth have had mixed results in supporting the health of Main Street businesses over the years, in contrast to more targeted metrics closely associated with these businesses [35]. Evidence-based and data-driven methods specific to Main Street are recommended, specifically through a standalone Main Street data dashboard to monitor their health and improve policy decisions [39]. Table I highlights documented qualitative and quantitative characteristics that can help policymakers identify, segment, and quantify the health of Main Street commercial corridors and businesses when developing a data-driven dashboard.

Example of a Main Street dashboard metric: Because Main Street businesses include restaurants, a potential dashboard can compare the median PPP loans received by restaurants in Seattle based on the business owner's race/ethnicity and restaurant status
(Figure 4). This reveals that while White restaurant owners account for $28 \%$ of all full-service Seattle restaurant owners, they received a median relief loan of almost $\$ 80,000$ which is $\$ 25,000$ higher than all full-service restaurants. A more comprehensive Main Street dashboard bringing together different tracked Main Street metrics and indicators can be further developed and implemented.

Limitations of approach: While such a framework can help better support vitality and equity objectives in urban regions in the context of COVID-19 and beyond, efforts to monitor and quantify Main Street businesses' impacts have faced difficulties due to a lack of consistent and agreed-upon definitions [39]. At the same time, officials can build on existing quantitative studies, metrics, and sources to build this dashboard $[35,39]$. If the focus is to improve their urban communities' vitality and to support equity objectives, regional policymakers will have to engage data specialists and local stakeholders to develop indicators and identify data sources that suit their unique local needs. 
Full Service $\square$ Limited Service

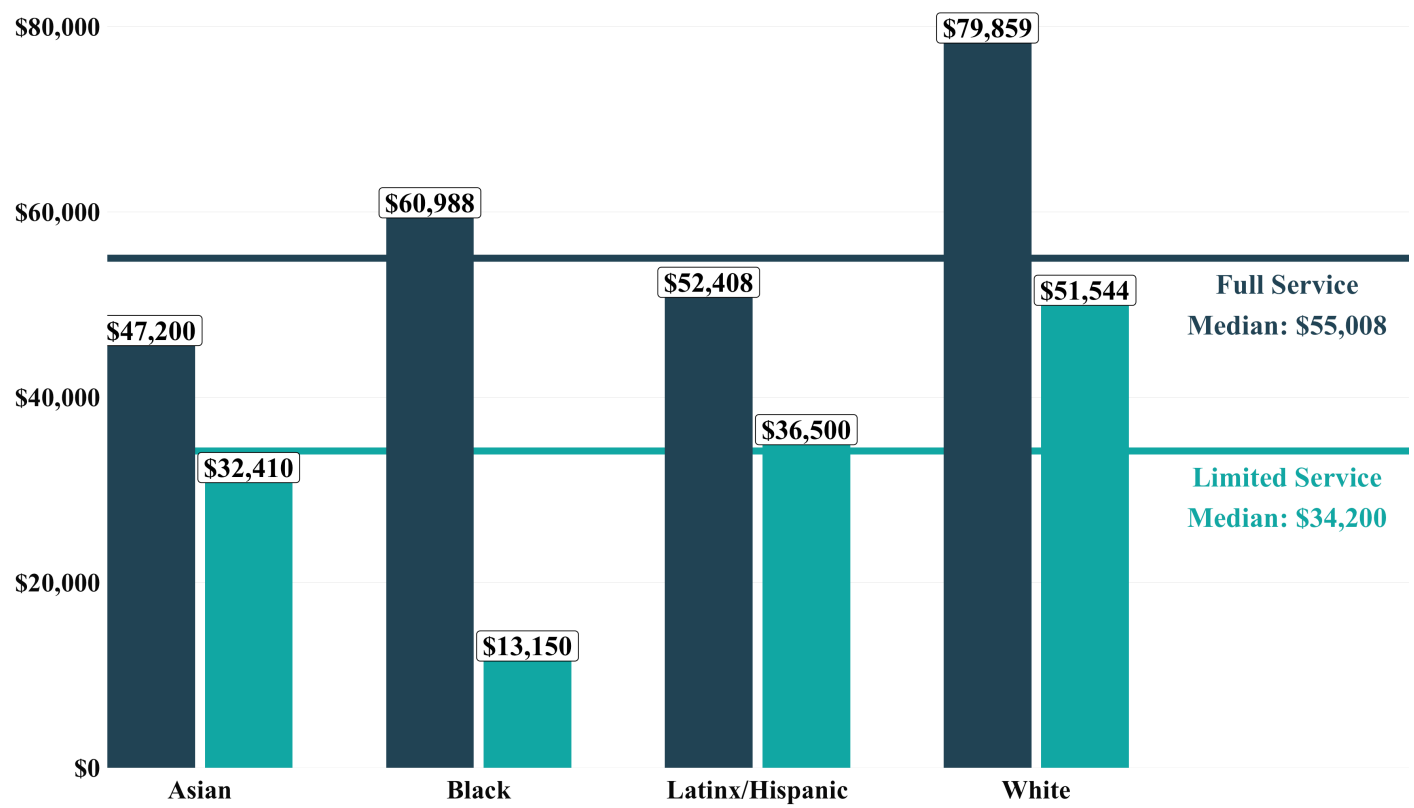

Figure 4: A Main Street dashboard can track metrics relevant to restaurants and other Main Street-focused industries. In this case, the median pandemic relief received through the distribution of PPP loans in Seattle is shown, by restaurant owner's race and ethnicity (April-August 2020) [22].

\section{Addressing digital disparities with technology policy responses tailored to Main Street}

We highlighted the value for policymakers to be better connected to the realities of Main Street businesses through a Main Street analytical framework. As the COVID-19 pandemic revealed, these businesses have specific needs. For instance, they face digital adoption disparities in relation to other firms that hamper their ability to adapt: $13 \%$ of small businesses lack the required skills to sell products online or enable teleworking, and $62 \%$ of small North American firms are still in the early stages of digitalization [41]. Implementing tailored technology policy responses, such as increasing technology adoption of Main Street businesses, can improve their capacity to adapt to the future of work.

Digitalization and Main Street resilience: Helping Main Street businesses make a digital transition towards e-commerce and increased digital capacity to support teleworking can improve their resilience. Indeed, there is a reported positive correlation between digitalization and the ability of small businesses to respond to public crises [42]: digitally advanced small businesses have the highest recovery and resilience from COVID-19 impacts than others [41]. Digitalization also helps small businesses generate revenue, maintain cash flow, and curb profit declines in crisis times [41].

While digitalization can enhance business resilience, technical and informational barriers in technology adoption must be overcome. Twelve percent of surveyed American companies reported that they lack insights into digitalization benefits, while $13 \%$ reported the lack of technology as another challenge [41]. In deciding whether to digitalize, businesses consider a technology's ease of use and usefulness [43]. However, most digitalization information is geared towards larger firms that incorrectly assume that all businesses will have the capacity to outsource this task [43]. Similarly, knowledge gaps surrounding digitalization options, including understanding security, privacy, and legal considerations [44], mean that small businesses avoid digitalization activities.

"Digital Main Street": Regional policymakers can address the technical and informational barriers highlighted above by implementing digitalization initiatives [45] that increase Main Street businesses' technology adoption. For example, Toronto's Digital Main Street is a public-private collaboration model that has seen the involvement of technology and accounting companies such as Facebook and Shopify to provide advice and services uniquely tailored to small businesses [46]. Small businesses receive support to launch an online store and are provided with an interdisciplinary team of professionals to help them develop and implement their digital transformation plan [46]. As a result, 15,000 businesses adopted digital tools and e-commerce platforms [47]. In cities that 
pose as technological centers like Seattle, there are opportunities to leverage partnerships with high-tech firms to support technology policy initiatives adapted to Main Street while alleviating potential negative downstream impacts on people, places, and profits.

Limitations of approach: Technology policy initiatives, like business digitalization, must account for possible negative risks, such as cybersecurity, systems maintenance, and obsolescence, and dependence on public and private entities to continue upkeep when small businesses lack technical capabilities [48]. If these programs are designed with accessibility, sustainability, and longevity in mind, with the end goal of ensuring independent operation of these digital technologies, these concerns can be addressed.

Beyond a Main Street framework: equity-based analyses in regional decision-making for a more inclusive and resilient post-pandemic recovery

The differential disparities that COVID-19 has laid bare on places, people, and profits in the US and cities like Seattle means that some regional organizations seek to make equity a central pillar of planning decisions. For instance, the Puget Sound Regional Council, the regional planning body governing Seattle and surrounding regions, is advancing a Regional Equity Strategy with an aspirational goal to address inequities experienced by historically marginalized communities [49]. In fact, equity-focused COVID-19 policies are said to have benefitted urban centers like Sydney, Milan, Seoul, and London by focusing on the local character of spaces (i.e., place) and the individuals in these places (i.e., people) [50]. Complementing a Main Street analytical framework, policymakers can build on lessons learned from government organizations in jurisdictions that have attempted to integrate equity-based analyses into the policy process.

\section{Equity policy aspirations to policy outcomes}

Initiatives supporting equity in both the policy process and policy outcomes have faced considerable challenges and required substantive efforts in jurisdictions like Australia and Canada [51], thus revealing equity aspirations alone in government-led organizations are insufficient. For instance, while Canada committed to integrating gender equality considerations in the policymaking process in all its departments and agencies in 1995, they were found to have a marginal influence on decision-making almost two decades later [52]. In other words, when there is a lack of an overall equity governance framework that provides equity tools and checklists, methodologies, data and metrics, and tailored training to policymakers, implementation of equity principles in decision-making will likely result in uneven outcomes.

Institutionalizing equity analysis: Regional planning entities can institutionalize equity analysis in policymaking to address the uneven implementation of equity policy aspirations, a practice that was adopted by federal entities in Canada that included: (1) implementing an overarching policy statement of intent; (2) establishing a responsibility center to support and monitor equity analysis across the organization; (3) development of tailored tools, guides, and checklists to support decision-makers applying equity analysis; (4) supporting training and ongoing monitoring and reporting of progress [53].

Limitations of approach: Institutionalizing equity analysis has been criticized as being fixated on policy processes rather than resulting in transformational systemic changes that require more actively engaging community stakeholders to ensure their needs are reflected in decisions [52]. However, it provides regional policymakers with a starting point to build upon existing practices so that equity aspirations result in policy outcomes while still exploring more integrated governance equity-focused strategies in regional bodies. Further, equity metrics, analysis, and tracking can be supported with an improved collection and reporting of gender and diversity disaggregated data. Potentially, these can be integrated into a data-driven Main Street dashboard to better monitor and respond to socioeconomic disparities previously highlighted.

\section{Conclusion}

The changing nature of workspaces because of the COVID-19 pandemic transformed urban landscapes and resulted in significantly varying and asymmetric impacts on diverse communities in the US and major urban metropolitan centers like Seattle. In preparing for a more resilient and inclusive future of work, policymakers can mobilize with data-driven tools and technology policy initiatives to better measure and mitigate the differential socioeconomic impacts while supporting urban vitality and equity goals, respectively. Specifically, a Main Street data-driven analytical framework can support policymakers in tailoring place, people, and profit-based strategies to revitalization, such as supporting technology adoption in small and local businesses. Further, given the disproportionate impacts on historically marginalized communities, institutionalizing equity analysis in regional decision-making systems can complement a Main Street framework. In the context of ever-increasing data availability and the ubiquity of Main Streets in 
diverse US regions-whether in large metropolitan urban centers or small-town rural areas-policymakers across the US can tailor this Main Street framework to suit local conditions and the unique needs of their communities.

\section{Acknowledgements}

The authors would like to thank Prof. Juste Rajaonson from the Department of Urban and Tourism studies at UQAM, MIT $S P R$, the 2020 MIT Policy Hackathon organizers and the peer reviewers for facilitating this publication.

\section{Citation}

Haddad, F. G., Raheem, Z., Mattingly, P. J., Mishra, S., \& Patki, M. A Main Street framework leveraging data and technology for good. MIT Science Policy Review 2, 99-107 (2021). https://doi.org/10.38105/spr.msm75t69ig.

\section{Open Access}

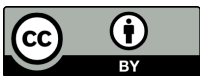

This MIT Science Policy Review article is licensed under a Creative Commons Attribution 4.0 International License, which permits use, sharing, adaptation, distribution and reproduction in any medium or format, as long as you give appropriate credit to the original author(s) and the source, provide a link to the Creative Commons license, and indicate if changes were made. The images or other third party material in this article are included in the article's Creative Commons license, unless indicated otherwise in a credit line to the material. If material is not included in the article's Creative Commons license and your intended use is not permitted by statutory regulation or exceeds the permitted use, you will need to obtain permission directly from the copyright holder. To view a copy of this license, visit http: //creativecommons.org/licenses / by $/ 4.0 /$.

\section{References}

[1] Seattle Times. What will happen to Seattle's tall, empty, office towers when COVID-19 ends? Online: https://www.seattletimes.com/business/realestate/what-will-happen-to-seattles-tall empty-office-towers-when-covid-19-ends/

(2020). Accessed June 2021

[2] Bick, A., Blandin, A. \& Mertens, K. Work from Home Before and After the COVID-19 Outbreak. Working Papers 2017, Federal Reserve Bank of Dallas (2020). https://doi.org/ 10.24149/wp2017r2.

[3] US Small Business Pulse Survey data. Online: https:// portal. census.gov/pulse/data/ (2021).

[4] VTS. VTS office demand index monthly report: April 2021. Online: https://on.vts.com/rs/811-SJQ-803/images/ vts-office-demand-index-april-2021.pdf

(2021). Accessed May 2021.

[5] Cushman \& Wakefield. Sublease space at a Glance: Pandemic effects one year in: Insights: United States. Online: https://www. cushmanwakefield.com/en/unitedstates/insights/sublease-space-at-a-glance (2021). Accessed June 2021.

[6] Colliers International. Monthly Report: October 2020 Seattle Sublease Report. Online: https://www.colliers.com/ en/research/puget-sound/october-2020-seattlesublease-report Accessed June 2021.
[7] Pagano, M., Wagner, C. \& Zechner, J. Disaster resilience and asset prices. SSRN Electronic Journal (2020). https://doi. org/10.2139/ssrn.3603666.

[8] Balla-Elliott, D., Cullen, Z., Glaeser, E. L., Luca, M. \& Stanton, C. Business reopening decisions and demand forecasts during the covid-19 pandemic. SSRN Electronic Journal (2020). https: //doi.org/10.3386/w27362.

[9] Fairlie, R. W. The impact of COVID-19 on small business owners: Continued losses and the partial rebound in May 2022. NBER Working Paper w27462 (2020).

[10] Liu, S. \& Su, Y. The impact of the COVID-19 pandemic on the demand for density: evidence from the US housing market. Federal Reserve Bank of Dallas, Working Papers 2020 (2020). https://doi.org/10.24149/wp2024r1.

[11] Zillow 2020 urban-suburban market report. Online: https://www.zillow.com/research/2020-urbsuburb-market-report-27712/ (2020). Accessed May 2021.

[12] Apartment List National Rent Report. Online: https://www. apartmentlist.com/research/national-rent-data (2021). Accessed June 2021.

[13] The Aspen Institute. The COVID-19 Eviction Crisis: an Estimated 30-40 Million People in America Are at Risk. Online: https://www. aspeninstitute.org/blog-posts/thecovid-19-eviction-crisis-an-estimated-30-40million-people-in-america-are-at-risk/

(2020). Accessed June 2021.

[14] Puget Sound Regional Council. Displacement risk mapping Online:https://www.psrc.org/displacement-riskmapping Accessed April 2021.

[15] Autor, D. \& Reynolds, E. B. The nature of work after the COVID crisis: Too few low-wage jobs. Online: https://www.brookings.edu/research/the-natureof-work-after-the-covid-crisis-too-few-lowwage-jobs/(2020). Accessed May 2021.

[16] Seattle Times. The deepening economic divide: how the pandemic has hurt small businesses. Online: https: //www.seattletimes.com/business/economy/thedeepening-economic-divide-how-the-pandemichas-hurt-small-businesses/ (2021). Accessed May 2021.

[17] SCORE. The megaphone of main street: the impact of COVID-19. Online: https://www.seattletimes.com/ business/economy/the-deepening-economic-dividehow-the-pandemic-has-hurt-small-businesses/ (2020). Accessed April 2021.

[18] Kim, O. S., Parker, J. A. \& Schoar, A. Revenue Collapses and the Consumption of Small Business Owners in the Early Stages of the COVID-19 Pandemic. National Bureau of Economic Research (2020). https://doi.org/10.3386/w28151.

[19] COVID-19 Mobility Trends Reports, Apple. Online: https:// covid19.apple.com/mobility/(2021).

[20] Bartik, A. et al. How Are Small Businesses Adjusting to COVID-19? Early Evidence from a Survey. SSRN Electronic Journal (2020). https://doi.org/10.3386/w26989.

[21] Bartik, A. et al. The targeting and impact of paycheck protection program loans to small businesses. SSRN Electronic Journal (2020). https:/doi.org/10.3386/w27623.

[22] Paycheck Protection Program (PPP) data, Small Business Administration (SBA). Online: https://www.sba. gov/funding-programs/loans/Covid-19-reliefoptions/paycheck-protection-program/ppp-data (2020).

[23] Ruprecht, M. M. et al. Evidence of social and structural COVID-19 disparities by sexual orientation, gender identity, and race/ethnicity in an urban environment. Journal of Urban Health 98, 27-40 (2021). https://doi.org/10.1007/s11524020-00497-9.

[24] Tirupathi, R. et al. COVID-19 disparity among racial and ethnic minorities in the US: A cross sectional analysis. Travel Medicine 
and Infectious Disease 38, 101904 (2020). https : / / doi . org/ 10.1016/j.tmaid.2020.101904.

[25] McKinsey \& Company. COVID-19's effect on minority-owned small businesses. Online: https://wiw-report.s3. amazonaws.com/Women in the Workplace_2020.pdf (2020). Accessed May 2021.

[26] Ali, S., Asaria, M. \& Stranges, S. COVID-19 and inequality: are we all in this together? Canadian Journal of Public Health 111 415-416 (2020). https://doi.org/10.17269/s41997$020-00351-0$.

[27] Adams-Prassl, A., Boneva, T., Golin, M. \& Rauh, C. Inequality in the impact of the coronavirus shock: Evidence from real time surveys. Journal of Public Economics 189, 104245 (2020).

[28] Economic Policy Institute. Black workers face two of the most lethal preexisting conditions for coronavirus-racism and economic inequality. Online: https://www.epi.org/ publication/black-workers-covid/ Accessed June 2021.

[29] McKinsey \& Company. Women in the Workplace. Online:https://wiw-report.s3.amazonaws.com/Women in the Workplace 2020.pdf (2020). Accessed May 2021.

[30] Seattle Jobs Initiative. Covid-19 recession and recovery brief. Online: https://www.seattle.gov/documents/ Departments/economicDevelopment/workforce/ COVID-19-Recession-and-Recovery-Brief잉 (1) . pdf (2020). Accessed June 2021.

[31] Washington State Employment Security Department Unemployment insurance statistics and data. Online: https: //esd.wa.gov/newsroom/unemployment-statistics (2021).

[32] 2019 Population Estimates, US Census Bureau. Online: https://www. census.gov/newsroom/press-kits/ 2020/population-estimates-detailed.html (2019).

[33] Seidman, K. F. Revitalizing commerce for American cities: A practitioner's guide to Urban Main Street Programs (Fannie Mae Foundation, 2004).

[34] Neamtu, B. \& Leuca, C. R. Adapting the US main street philosophy and program to the romanian urban context. Could it possibly work? Transylvanian Review of Administrative Sciences 2, 80-95 (2006).

[35] Talen, E. \& Jeong, H. What is the value of 'main street'? Framing and testing the arguments. Cities 92, 208-218 (2019). https: //doi.org/10.1016/j.cities.2019.03.023.

[36] Mehta, V. Small businesses and the vitality of main street. Journal of Architectural and Planning Research 28, 271-291 (2011). http://www.jstor.org/stable/43030948.

[37] Americas Society/Council of The Americas. Bringing vitality to main street: how immigrant small businesses help local economies grow. Online: https://www.ascoa.org/articles/bringing-vitality-main-streethow-immigrant-small-businesses-help-localeconomies-grow (2015). Accessed May 2021.

[38] Florida, R. Cities and the creative class. City \& Community 2, 3-19 (2003). https://doi.org/10.1111/1540-6040. 00034

[39] Current state and future of Toronto's retail main streets. Online: https://www. toronto.ca/wp-content/uploads/2020/ 11/9826-Current-State-and-Future-of-TorontosRetail-Main-Streets-Full-Report-Final-Jan2020-compressed.pdf (2020). Accessed June 2021.

[40] Muske, G. \& Woods, M. Micro businesses as an economic development tool: what they bring and what they need. Community Development Society. Journal 35, 97-116 (2004). https://doi.org/10.1080/15575330409490124.

[41] CISCO. 2020 Small Business Digital Transformation: a snapshot of eight of the world's leading markets. Online: https://www.cisco.com/c/dam/en_us/solutions/ small-business/resource-center/small-businessdigital-transformation.pdf (2020). Accessed May 2021.
[42] Guo, H., Yang, Z., Huang, R. \& Guo, A. The digitalization and public crisis responses of small and medium enterprises: Implications from a COVID-19 survey. Frontiers of Business Research in China 14, 19 (2020). https://doi.org/10. 1186/s11782-020-00087-1.

[43] Ritz, W., Wolf, M. \& McQuitty, S. Digital marketing adoption and success for small businesses: The application of the do-it-yourself and technology acceptance models. Journal of Research in Interactive Marketing 13, 179-203 (2019). https: //doi.org/10.1108/JRIM-04-2018-0062.

[44] Fan, Q. Factors affecting adoption of digital business: Evidence from Australia. Global Journal of Business Research 10, 79-84 (2016).

[45] Molinillo, S. \& Japutra, A. Organizational adoption of digital information and technology: a theoretical review. The Bottom Line 30, 33-46 (2017). https : / / doi .org/10.1108/BL-012017-0002.

[46] City of Toronto. City of Toronto further expands Digital Main Street program to help local businesses during the COVID-19 pandemic. Online: https://www.toronto.ca/news/cityof-toronto-further-expands-digital-mainstreet-program-to-help-local-businessesduring-the-covid-19-pandemic (2020). Accessed April 2021.

[47] Ontario Business Improvement Area Association. A hand up for small business - digital main street 2020 progress report. Online: https://obiaa.com/wp-content/uploads/2021/05/ DMS-Keeping-Small-Businesses-Connected-May2021-Progress-Report_LR.pdf (2021). Accessed April 2021.

[48] Demiroglu, N. Directions of digitalization of small business. In Proceedings of the 2nd International Scientific and Practical Conference "Modern Management Trends and the Digital Economy: from Regional Development to Global Economic Growth" (MTDE 2020) (Atlantis Press, Yekaterinburg, Russia, 2020).

[49] Puget Sound Regional Council. VISION 2050 - Regional Equity Strategy. Online: https://www.psrc.org/ sites/default/files/vision-2050-plan.pdf (2020). Accessed April 2021.

[50] Cave, B., Kim, J., Viliani, F. \& Harris, P. Applying an equity lens to urban policy measures for COVID-19 in four cities. Cities \& Health 1-5 (2020). https://doi.org/10.1080/23748834. 2020.1792070.

[51] Hankivsky, O. Gender mainstreaming in Canada and Australia: A comparative analysis. Policy and Society 27, 69-81 (2008). https://doi.org/10.1016/j.polsoc.2008.07.006.

[52] McNutt, K. \& Béland, D. Implementing an integrated governance strategy: the quest for gender mainstreaming in Canada. American Review of Canadian Studies 45, 467-485 (2015). https://doi.org/10.1080/02722011.2015.1116591.

[53] Government of Canada. 2009 Spring Report of the Auditor General of Canada. Online: https://www.oag-bvg.gc.ca/ internet/english/parl oag_200905 e 32545.html (2009). Accessed May 2021. 